\title{
Late gadolinium enhancement in cardiac sarcoidosis predicts ICD implantation and appropriate discharge
} Joyce L Wong*1, Francisco Alpendurada1, Masliza Mahmod', Elisabeth Burman1, Monica Deac1, Dana Dawson11, Rory O'Hanlon²,1, Athol Wells ${ }^{3}$, Dudley Pennell ${ }^{1}$ and Sanjay Prasad ${ }^{1}$

\author{
Address: ${ }^{1}$ CMR Unit, Royal Brompton and Harefield Foundation Trust, London, UK, ${ }^{2}$ CMR Unit, Royal Brompton and Harefield Foundation Trust, \\ London, UK and ${ }^{3}$ Royal Brompton Hospital, London, UK \\ * Corresponding author
}

from I3th Annual SCMR Scientific Sessions

Phoenix, AZ, USA. 21-24 January 2010

Published: 21 January 2010

Journal of Cardiovascular Magnetic Resonance 20 I0, I2(Suppl I):OI doi:I0.I I86/I532-429X-I2-SI-OI

This abstract is available from: http://jcmr-online.com/content//2/SI/OI

(c) 2010 Wong et al; licensee BioMed Central Ltd.

\section{Introduction}

Cardiac sarcoidosis is associated with sudden arrhythmic death, conduction abnormalities and heart failure. Occult disease is frequently found at autopsy although its significance remains unclear. Late gadolinium enhancement (LGE) on cardiac magnetic resonance (CMR) imaging permits detection of granulomatous cardiac infiltration and myocardial fibrosis.

\section{Purpose}

We sought to establish whether CMR diagnosis of cardiac sarcoidosis correlates with clinical outcome in this complex disease.

\section{Methods}

96 consecutive patients with sarcoidosis were referred to our centre for CMR between 2002 and 2007 (46 M, 50 F; mean age 57 years). Outcomes in two cohorts distinguished by evidence of LGE were retrospectively assessed (mean follow-up 3.5 years). Left ventricular (LV) volumes, ejection fraction (EF) and mass were evaluated using semi-automated analysis software and indexed to body surface area. Continuous variables were reported as mean \pm standard deviation; groups (based on the presence or absence of LGE) were compared using a t-test or Fisher's exact test.

\section{Results}

LGE was observed in 31 out of 96 (32\%) patients. No significant difference was seen in all-cause death or hospitalisation for a cardiovascular event between the LGE+ and LGE- cohort. The LGE+ cohort had a significantly greater rate of ICD implantation (7 vs $1, \mathrm{p}<0.0005)$ and appropriate ICD discharge ( 4 vs $0, p<0.005$ ). Notably, only four patients had right ventricular LGE+; all required defibrillator (ICD) implantation and sustained appropriate ICD discharge. There was no difference in other secondary outcomes such as pre-ICD implantation sustained ventricular tachycardia, pacemaker implantation rate or escalation of heart failure therapy. Amongst LGE+ individuals, there was a significant reduction in biventricular EF (LVEF $50 \pm 13.0 \%$ vs. $64 \pm 10 \%$, p < 0.05 ; RVEF $49 \pm 13$ vs. $58 \pm$ $9 \%, \mathrm{p}<0.05)$. RVEDV was also significantly greater $(173$ \pm 14 vs.137 $\pm 5 \mathrm{mls}, \mathrm{p}<0.0065)$, although not LVEDV $(105 \pm 5.9$ vs. $132 \pm 7.9 \mathrm{mls}, \mathrm{p}<0.0066)$. The distribution of LGE did not appear to correlate with outcome. The two groups did not differ in the incidence of biopsy-proven sarcoidosis (48/96 cases), pre-referral cardiac symptoms or duration of follow-up. Within this cohort, only five patients had STIR imaging clearly suggestive of active cardiac sarcoidosis.

\section{Conclusion}

In this cohort, presence of cardiac LGE in sarcoidosis is associated with increased ICD implantation and appro- 
priate discharge but not worse mortality or hospitalization outcome, despite an associated biventricular reduction in ejection fraction. RV LGE may predict a requirement for ICD implantation. Further prospective research is needed to improve understanding of this complex disease.

Publish with Bio Med Central and every scientist can read your work free of charge

"BioMed Central will be the most significant development for disseminating the results of biomedical research in our lifetime. " Sir Paul Nurse, Cancer Research UK

Your research papers will be:

- available free of charge to the entire biomedical community

- peer reviewed and published immediately upon acceptance

- cited in PubMed and archived on PubMed Central

- yours - you keep the copyright 